thronisiert, diese blieben ihre Ratgeberinnen. In Ägypten herrschten oftmals und über lange Zeiten auch Frauen. Die Weltanschauung bleibt für uns in der Mythologie erhalten. Diese spiegelt die Lebensweise und ihre Strukturprinzipien wider: „Ich bin Isis, die Herrin aller Länder. Ich gab und erließ Gesetze für die Menschen, die niemand ändern kann. Ich machte das Recht stärker als Gold und Silber. Ich vereinigte Mann und Frau. Ich verhängte Strafen für die Ungerechten. Ich gewährte Gnade den Bittenden. Mit mir obsiegt das Recht“. Dieser aus einer Isis-Hymne stammende, sicher 5.000 Jahre alte Text ist einer der vielen Belege, die Degen gefunden und für die von ihr konzipierte Ausstellung zusammengestellt hat.

Der Geschichte der Gerechtigkeitssuche nachzuspüren heißt notwendig auch nachvollziehen zu müssen, wie Männer versucht haben, sich der Fähigkeiten der Frauen zu bemächtigen und deren Einfluss zu beschneiden. Die Normierung universeller Regeln, ihre Umsetzung in Vorschriften, ist ein solcher Versuch. Nicht mehr Erfahrung dient als Legitimation für Regeln, sondern Macht und Herrschaft. Es handelt sich um einen jahrtausendelangen Prozess der Entmachtung und Entfremdung von Frauen, in je unterschiedlicher kultureller Ausprägung. Auch die Entwicklung einer so genannten Rechtswissenschaft hat vor allem diese Funktion: Ausschluss der Frauen von der Rechtssetzung und -ausübung. Die uns allen bekannten Texte aus den 20er Jahren des vorigen Jahrhunderts über die Unfähigkeit der Frauen zum juristischen Beruf aufgrund ihrer Emotionalität erscheinen vor diesem Hintergrund noch einmal in ganz anderer Weise als decouvrierend für ihre Autoren und das, was jene repräsentieren. Der Kampf der Frauen um Gleichberechtigung war immer, das belegen Degens Forschungen, ein Kampf um eine gerechte Ordnung für alle. Das Symbol der Justitia, seit Jahrtausenden entwickelt, erweist sich so als ein widerständiger ideengeschichtlicher Ort zur Tradierung des weiblichen Bewusstseins vom Recht und den Bedingungen einer gerechten Ordnung.

Barbara Degen hat eine Fülle von Material aus allen Epochen zusammengestellt und präsentiert dies in der von ihr erarbeiteten Ausstellung. Der vorliegende Band bietet aber nicht nur für Ausstellungsbesucherinnen die Möglichkeit, das eine oder andere noch einmal nachzuhalten. Auch für jene, die die Ausstellung noch nicht sehen konnten, bietet die „Geschichte und Symbolik der Gerechtigkeit“ eine spannende und erhellende Lektüre, auch zur Stärkung des (beruflichen) Selbst-Bewusstseins. (Sabine Heinke)

Die Wanderausstellung „Füllhorn, Waage, Schwert - Justitia ist eine Frau“ wird erstmalig vom 6. bis zum 24. Mai 2009 in Berlin zu sehen sein und am 6. Mai um 18.30 Uhr im BMJ von Bundesjustizministerin Brigitte Zypries, Dr. Barbara Degen und Annette Kuhn, der Vorsitzenden des gemeinnützigen Vereins „Haus der Frauengeschichte e.V., Bonn“, eröffnet werden.

\title{
Rezension: Die essentielle Frauenchronik
}

Die essentielle Frauen-Chronik. Das Jahr 2008 aus weiblicher Sicht. Hrsg.: Sharon Adler, Stefanie Denkert, Silvy Pommerenke; AVIVA Berlin und Verlag Dashöfer Hamburg, 2008.

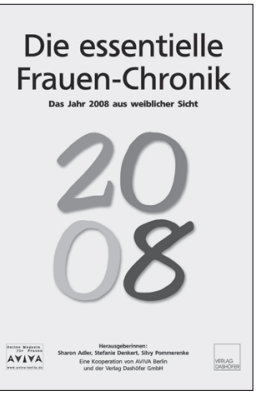

„Eine Erfolgsgeschichte“ titelte die FAZ kürzlich einen Beitrag zu den vergangenen 60 Jahren der Bundesrepublik. Grundlage des Artikels sind u.a. Ergebnisse einer Umfrage des Instituts für Demoskopie Allensbach 2009. Unter anderem wurden die Befragten aufgefordert, ein Wachsfigurenkabinett mit den wichtigsten Politiker der letzten 60 Jahre einzurichten. Aus einer Liste mit 28 Namen konnten die Befragten diejenigen auswählen, die unbedingt ausgestellt werden sollten. Unter den 28 gelisteten Personen befand sich mit Bundeskanzlerin Angela Merkel genau eine einzige Frau.

Wenn man die acht Bundeskanzler und neun Bundespräsidenten sowie ausgewählte - nicht alle - Staatsratsvorsitzende und Vorsitzende des Ministerrates der DDR zusammenzählt, bleiben in der Tat nicht viele freie Plätze. Aber warum Erich Ollenhauer und nicht Helene Weber, eine der vier „Mütter des Grundgesetzes“, die bereits an der Weimarer Verfassung mitwirkte und im Parlamentarischen Rat als Schriftführerin Mitglied des Präsidiums war. Sie war von 1919 bis 1962 mit Aus- nahme der zwölf Jahre des Nationalsozialismus ununterbrochen Parlamentsabgeordnete. Warum Kurt Schumacher, aber nicht Helene Wessel, die seit 1949 Vorsitzende der Zentrumspartei war, damit die erste Frau an der Spitze einer Partei in Deutschland und die erste weibliche Fraktionsvorsitzende. Warum Thomas Dehler und nicht Sabine Leutheusser-Schnarrenberger, die erste Justizministerin. Es fehlt auch Hilde Benjamin, die von 1954 bis 1989 Mitglied des Zentralkomitees der SED und von 1953 bis 1967 Ministerin der Justiz war.

Warum geraten Frauen so schnell in Vergessenheit? Warum werden sie aus der Geschichte einfach ausgeblendet? Selbst in der aktuellen medialen Berichterstattung sind Frauen nach wie vor unterrepräsentiert und werden mit ihren Leistungen nicht ausreichend dargestellt. Die Herausgeberinnen der „Essentiellen Frauenchronik 2008“ Sharon Adler, Stefanie Denkert und Silvy Pommerenke machen Frauen sichtbar. Die Frauenchronik enthält zahllose Jubiläen wie Geburtstage, Todestage, Preisverleihungen und viele weitere Ereignisse, die herausragende Frauen und ihre Lebensläufe und Leistungen darstellen. Unter dem Datum 28. August 2008 ist z.B. zu lesen, dass 1948 in Dortmund der Deutsche Juristinnenbund (neu) gegründet wurde und nun seinen 60. Geburtstag feierte.

Ein nützliches Buch über die Erfolgsgeschichte der Frauen zum Lesen, Durchblättern, Nachschlagen und Weiterempfehlen. (Anke Gimbal) 